\title{
MEDIAÇÃO E CONCILIAÇÃO: APLICAÇÃO PRÁTICA NA JUSTIÇA FEDERAL E PERSPECTIVAS FRENTE ÀS NOVAS TECNOLOGIAS
}

\author{
MEDIATION AND CONCILIATION: PRACTICAL APPLICATION IN FEDERAL JUSTICE AND \\ PERSPECTIVES IN VIEW OF NEW TECHNOLOGIES
}

\author{
Tatiana Boghourian \\ Mestranda na Faculdade Alfa-Fadisp. \\ Servidora Pública Federal \\ tboghour@hotmail.com \\ Jânio Urbano Marinho Júnior \\ Mestre pela Faculdade Alfa-Fadisp. \\ Defensor Público Federal em São Paulo. \\ Vice-Diretor Geral da Escola Nacional \\ da Defensoria Pública da União \\ janiomarinho@hotmail.com
}

\section{RESUMO}

O objetivo deste artigo é convidar o leitor a uma reflexão sobre a utilização da conciliação e mediaçấo como instrumentos de gerenciamento dos processos e sua efetividade no desiderato de trazer uma soluçáo mais adequada e justa aos casos em litígio. Foram apresentados dados estatísticos colhidos pelo Conselho Nacional de Justiça revelando em números os efetivos resultados. Ademais, pretende-se mostrar que na atualidade a utilização da mediação e conciliação não se limita às demandas envolvendo particulares, sendo uma realidade positivada no ordenamento jurídico a qual incluiu a Administração Pública no dever de buscar a soluçáo consensual das demandas. Dá-se um enfoque, por fim, à utilização perante à Justiça Federal e ao reflexo desses mecanismos nos processos de competência federal, o que acaba por abranger grandes litigantes e demandas de massa, tornando-se, dessa forma, uma realidade nos dias atuais. É com esse olhar que adentramos no estudo da conciliação e mediação.

Palavras-chave: Direito. Conciliação. Mediação. 


\begin{abstract}
The purpose of this article is to invite the reader to reflect on the use of conciliation and mediation as tools for managing the processes and their effectiveness in the desire to bring a more adequate and fair solution to the cases in dispute. Statistical data were collected by the National Council of Justice, revealing in figures the actual results. In addition, it is intended to show that at present the use of mediation and conciliation is not limited to the demands involving individuals, being a positive reality in the legal system which included the Public Administration in the duty to seek the consensual solution of the demands. Finally, there is a focus on the use before the Federal Court and the reflection of these mechanisms in the federal jurisdiction proceedings, which ends up covering large litigators and mass demands, becoming, in this way, a reality in the present day. It is with this look that we enter into the study of conciliation and mediation.
\end{abstract}

Keywords: Law. Conciliation. Mediation.

Data de submissão: 28/02/2020

Data de aceitação: 26/04/2020

\title{
SUMÁRIO
}

INTRODUÇÃO 1. DA CONCILIAÇÃO E DA MEDIAÇÃO 2. ASPECTOS ATUAIS DOS MEIOS ALTERNATIVOS DE RESOLUÇÁO DE CONFLITOS: AS NOVAS TECNOLOGIAS E AS RESOLUÇÓES ON-LINE DE DISPUTAS 3. PRINCIPAIS ASPECTOS DA CONCILIAÇÃO NA JUSTIÇA FEDERAL. CONSIDERAÇÓES FINAIS.

\section{INTRODUÇÃO}

No Mito de Sísifo, o personagem em questão foi capturado pelos Deuses do Olimpo por desafiá-los e a ele foi imposta uma punição. Ele teria: para toda a eternidade, de empurrar uma pedra em uma montanha até seu topo; a pedra entâo rolaria para baixo e ele novamente teria que começar tudo de novo. Como Sísifo, muitos veem o Judiciário como uma atividade executada arduamente e infindável.

De fato, os homens, desde o estado de natureza referido por Hobbes, até os dias atuais, convivem com conflitos de interesses. Historicamente, a humanidade passou por vários estágios em termos de solução para tais conflitos. A lei do mais forte hoje cede espaço para 
a solução judiciária. Nessa toada, o Judiciário desempenha o importante papel da tentativa da pacificação social. Como no mito de Sísifo, essa atividade se mostra inesgotável.

No cenário atual, voltamos nossos olhares para o papel do Judiciário. Será que podemos dizer que a pacificação social pode ser resumida ao papel tradicionalmente conferido ao juiz, de proferir sentenças para a soluçáo das demandas? Evidentemente que não. Vivemos tempos em que saltam aos olhos o desequilíbrio entre a procura por decisões judiciárias e a capacidade de proferi-las. Diante disso, a chamada "cultura da sentença", que tem como consequência significativo número de processos e de recursos, hoje cede espaço para meios alternativos de solução do conflito, ou, como alguns preferem, meios adequados de soluçấo do conflito.

Inegavelmente a maior celeridade é um dos pontos importantes desses mecanismos, contudo, o objetivo principal, sem dúvida, é dar às partes uma solução mais adequada e justa como forma de efetivo acesso à justiça. É, assim, um dos instrumentos do desiderato da pacificação social, não sendo, contudo, um fim em si mesmo. A solução do litígio de forma mais justa nem sempre será albergada pela mediação e a conciliação, por vezes, a sentença, produção de provas, instrução, atendem melhor as peculiaridades do caso concreto, solução que somente poderá ser compreendida pelas lentes do órgáo julgador.

A evolução do contexto normativo perpassa de uma faculdade do magistrado à previsão de utilização obrigatória. Os entes envolvidos também se ampliam, contando atualmente com a possibilidade expressa de conciliação envolvendo a Administração Pública.

Com isso, os órgãos jurisdicionais estaduais e federais de vários níveis vêm inserindo a solução consensual dos conflitos o que acaba por abranger grandes litigantes e demandas de massa, tornando-se mais abrangentes os resultados.

Não se pode perder de vista, por fim, que todas essas questóes ganham um novo colorido, novas potencialidades, diante do avanço tecnológico da nossa atual sociedade, que se encontra no limiar de uma Quarta Revoluçáo Industrial, ${ }^{1}$ de maneira que certamente essas novas tecnologias podem contribuir para o desenvolvimento desses meios adequados de resolução de conflitos, inclusive perante a Justiça Federal.

\section{DA CONCILIAÇÁO E DA MEDIAÇÃO}

Nos últimos anos houve uma ampla reforma do Poder Judiciário buscando soluçóes alternativas de conflito como a mediação e a conciliação, incorporadas ao ordenamento jurídico. Aqui, apenas um esclarecimento: meios alternativos de solução do conflito vão muito além da mediação e conciliação. Poderiam ser citadas inúmeras outras técnicas, mas, considerando que a mediação e a conciliação se mostram mais presentes no dia a dia do judiciário, acabam tendo um destaque maior.

1 Conforme ensina SCHWAB, Klaus. A quarta Revoluçáo Industrial. Tradução de Daniel Moreira Miranda. São Paulo: Edipro, 2016. 
A discussão a respeito desses meios alternativos (adequados) de solução de conflitos nos remete, inquestionavelmente, ao tema do acesso à justiça, que é referência ao trabalho desenvolvido por Mauro Cappelletti e Bryant Garth, ${ }^{2}$ os quais ensinam que o acesso efetivo à justiça vem sendo crescentemente aceito como um direito social básico nas modernas sociedades. A partir de amplo estudo sobre a questáo, esses autores observaram que existem obstáculos comumente encontrados na efetivação do acesso à justiça, propondo assim soluçôes aptas a superá-los. Com efeito, afirmaram que:

Um exame dessas barreiras ao acesso, como se vê, revelou um padrão: os obstáculos criados por nossos sistemas jurídicos são mais pronunciados para as pequenas causas e para os autores individuais, especialmente os pobres; ao mesmo tempo, as vantagens pertencem de modo especial aos litigantes organizacionais, adeptos do uso do sistema judicial para obterem seus próprios interesses. ${ }^{3}$

A partir daí, surgia a ideia das ondas de acesso à justiça. Como primeira onda desse movimento de acesso à justiça, constataram obstáculos de natureza econômica e que deveriam ser superados por meio da criação e desenvolvimento de mecanismos de assistência jurídica para os pobres. A necessidade de contratação de advogado, por exemplo, constituía efetivamente uma barreira ao ingresso nos Tribunais. Nessa perspectiva, ganha relevo o direito fundamental à assistência jurídica integral e gratuita aos que comprovarem insuficiência de recursos, previsto no artigo 5a, LXXIV, da Constituição da República. Merece destaque também a constitucionalização da Defensoria Pública (artigo 134 da Constituição da República).

Depois, na segunda onda, verificaram-se obstáculos de natureza organizacional, porque, ao lado dos direitos individuais, existiam também direitos/interesses de natureza coletiva ou difusa, os quais não eram albergados pela solução tradicional. Tais obstáculos deveriam ser ultrapassados por intermédio da tutela coletiva dos direitos.

$\mathrm{Na}$ terceira onda renovatória, inserem-se justamente os mecanismos de solução alternativa de soluçáo de litígios, na busca de solucionar problemas de natureza processual, pois estava em jogo a questáo da efetividade, que muitas vezes não era alcançada pelo processo contencioso judicial.

Interessante notar que, no Brasil, essas ondas não ocorreram em uma sequência cronológica, mas emergiram praticamente juntas, na década de 1980, por uma conjunção de fatores de cunho político, econômico, social, jurídico e cultural, como bem pontuado por Leslie Shérida Ferraz. ${ }^{4}$ Nesse mesmo contexto, objetivou-se transpor de uma vez todos os obstáculos do acesso à justiça.

\footnotetext{
2 CAPPETTI, Mauro; GARTH, Bryant. Acesso à justiça. Tradução de Ellen Gracie Northfleet. Porto Alegre: Sérgio Antonio Fabris Editor, 2002.

3 CAPPETTI, Mauro; GARTH, Bryant. Acesso à justiça. Tradução de Ellen Gracie Northfleet. Porto Alegre: Sérgio Antonio Fabris Editor, 2002, p. 28.

4 FERRAZ, Leslie Shérida. Acesso à Justiça. Uma análise dos Juizados Especiais Cíveis no Brasil. Rio de Janeiro: Editora FGV, 2010, p. 78.
} 
Como lembram Cintra, Grinover e Dinamarco, "vai ganhando corpo a consciência de que, se o que importa é pacificar, torna-se irrelevante que a pacificação venha por obra do Estado ou por outros meios, desde que eficientes". ${ }^{5}$

Especialmente, sobre o papel dos meios alternativos de resolução de conflitos, Watanabe ${ }^{6}$ leciona que:

A incorporação dos meios alternativos de resolução de conflitos, em especial dos consensuais, ao instrumental à disposição do Judiciário para o desempenho de sua funçáo de dar tratamento adequado aos conflitos que ocorrem na sociedade, não somente reduziria a quantidade de sentenças, de recursos e de execuçôes, como também, o que é de fundamental importância para a transformação social com mudança de mentalidade, propiciaria uma soluçáo mais adequada aos conflitos, com a consideraçẫo das peculiaridades e especificidades dos conflitos e das particularidades das pessoas neles envolvidas.

Ainda, segundo o mesmo autor ${ }^{7}$ :

O princípio da inafastabilidade do controle jurisdicional, inscrito no inciso XXXV do art. $5^{\circ}$ da Constituiçáo Federal, não significa um mero acesso formal aos órgãos judiciários. Assegura ele um acesso qualificado à justiça que propicie ao jurisdicionado a obtenção de tutela jurisdicional efetiva, tempestiva e adequada, enfim, um acesso a uma ordem jurídica justa.

Sem a inclusão dos chamados meios consensuais de solução de conflitos, como a mediação e a conciliaçấo, não teremos um verdadeiro acesso à justiça. Certo é que, em algumas espécies de controvérsia, como já ficou mencionado, faltaria o requisito de adequação à solução dada pelo critério da adjudicação.

Pode-se afirmar, assim, sem exagero, que os meios consensuais de soluçáo de conflito fazem parte do amplo e substancial conceito de acesso a justiça, como critérios mais apropriados do que a sentença, em certas situaçốes, pela possibilidade de adequação da solução à peculiaridades do conflito, à sua natureza diferenciada, às condiçóes e necessidades especiais das partes envolvidas. Trata-se, enfim, de um modo de se alcançar a justiça com maior equanimidade e aderência ao caso concreto.

5 CINTRA, Antonio Carlos Araujo; DINAMARCO, Cândido Rangel; GRINOVER, Ada Pellegrini. Teoria Geral do Processo. $27^{a}$ edição. São Paulo: Malheiros, 2011, p. 31/32.

6 WATANABE, Kazuo. Política pública do poder judiciário nacional para tratamento adequado dos conflitos de interesse. In: RICHA M. A.; PELUSO A. C. Conciliaçáo e mediaçáo: estruturação da política judiciária nacional. Rio de Janeiro: Forense, 2011. p. 02/03.

7 WATANABE, KAZUO. Acesso à Ordem Jurídica Justiça. Belo Horizonte: Ed. Del Rey LTDA, 2019, p. 82. 
Com a evolução do contexto normativo, tais institutos passam a ter maior destaque na produçáo legislativa. Exemplo disso é que tais institutos foram previstos no Código de Processo Civil (CPC) de 2015 (Lei 13.105/15), na Lei de Mediação (Lei 13.140/2015), na Resolução CNJ n. 125/2010 (a qual instituiu a Política Judiciária Nacional de tratamento aos Conflitos de Interesses e determinou a criação de Núcleos Permanentes de Métodos Consensuais de Solução de Conflitos) e na Resolução do Conselho da Justiça Federal (CNJ) n. 398/2016.

Especificamente no que tange ao Código de Processo Civil, o artigo $334,{ }^{8}$ caput, previu como etapa necessária a prévia realização da audiência de conciliação e mediação, sendo descabida, apenas se ambas as partes manifestarem, expressamente, desinteresse na composição consensual, ou quando não se admitir a autocomposição. Tamanha a importância que foi dada a tal etapa que o não comparecimento injustificado do autor ou do réu à audiência de conciliação será considerado ato atentatório à dignidade da justiça e sancionado com multa de até dois por cento da vantagem econômica pretendida ou do valor da causa, revertida em favor da União ou do Estado.

O esforço de disseminar a soluçáo consensual dos conflitos vem estampado no próprio corpo do texto normativo ao prever que o Estado promoverá, sempre que possível, a solução consensual dos conflitos $\left(\$ 2^{\circ}\right.$ do art. $\left.3^{\circ}\right) .^{9}$ Traz ainda como poder dever do juiz

8 Art. 334. Se a petição inicial preencher os requisitos essenciais e não for o caso de improcedência liminar do pedido, o juiz designará audiência de conciliação ou de mediação com antecedência mínima de 30 (trinta) dias, devendo ser citado o réu com pelo menos 20 (vinte) dias de antecedência.

$\$ 1^{\circ} \mathrm{O}$ conciliador ou mediador, onde houver, atuará necessariamente na audiência de conciliaçáo ou de mediação, observando o disposto neste Código, bem como as disposiçóes da lei de organizaçáo judiciária.

$\$ 2^{\circ}$ Poderá haver mais de uma sessão destinada à conciliação e à mediação, não podendo exceder a 2 (dois) meses da data de realização da primeira sessão, desde que necessárias à composição das partes.

$\$ 3^{\circ} \mathrm{A}$ intimação do autor para a audiência será feita na pessoa de seu advogado.

$\$ 4^{\circ} \mathrm{A}$ audiência não será realizada:

I - se ambas as partes manifestarem, expressamente, desinteresse na composiçâo consensual;

II - quando não se admitir a autocomposição.

$\$ 5^{\circ} \mathrm{O}$ autor deverá indicar, na petição inicial, seu desinteresse na autocomposição, e o réu deverá fazê-lo, por petição, apresentada com 10 (dez) dias de antecedência, contados da data da audiência.

$\$ 6^{\circ}$ Havendo litisconsórcio, o desinteresse na realização da audiência deve ser manifestado por todos os litisconsortes.

$\$ 7^{\circ} \mathrm{A}$ audiência de conciliação ou de mediação pode realizar-se por meio eletrônico, nos termos da lei.

$\$ 8^{\circ} \mathrm{O}$ nâo comparecimento injustificado do autor ou do réu à audiência de conciliação é considerado ato atentatório à dignidade da justiça e será sancionado com multa de até dois por cento da vantagem econômica pretendida ou do valor da causa, revertida em favor da Uniáo ou do Estado.

$\$ 9^{\circ}$ As partes devem estar acompanhadas por seus advogados ou defensores públicos.

$\$ 10$. A parte poderá constituir representante, por meio de procuração específica, com poderes para negociar e transigir.

$\$ 11$. A autocomposição obtida será reduzida a termo e homologada por sentença.

$\$ 12$. A pauta das audiências de conciliação ou de mediação será organizada de modo a respeitar o intervalo mínimo de 20 (vinte) minutos entre o início de uma e o início da seguinte.

9 Art. $3^{\circ}$ Não se excluirá da apreciação jurisdicional ameaça ou lesão a direito. 
promover a qualquer tempo a autocomposição. ${ }^{10}$ Dedica um capítulo inteiro sobre mediadores e conciliadores judiciais. ${ }^{11}$

$\$ 2^{\circ}$ O Estado promoverá, sempre que possível, a solução consensual dos conflitos

10 DOS PODERES, DOS DEVERES E DA RESPONSABILIDADE DO JUIZ

Art. 139. O juiz dirigirá o processo conforme as disposições deste Código, incumbindo-lhe:

$\mathrm{V}$ - promover, a qualquer tempo, a autocomposição, preferencialmente com auxílio de conciliadores e mediadores judiciais;

11 Dos Conciliadores e Mediadores Judiciais

Art. 165. Os tribunais criarão centros judiciários de solução consensual de conflitos, responsáveis pela realização de sessôes e audiências de conciliaçâo e mediaçáo e pelo desenvolvimento de programas destinados a auxiliar, orientar e estimular a autocomposiçáo.

$\$ 1^{\circ}$ A composição e a organização dos centros serão definidas pelo respectivo tribunal, observadas as normas do Conselho Nacional de Justiça.

$\$ 2^{\circ} \mathrm{O}$ conciliador, que atuará preferencialmente nos casos em que náo houver vínculo anterior entre as partes, poderá sugerir soluções para o litígio, sendo vedada a utilização de qualquer tipo de constrangimento ou intimidação para que as partes conciliem.

$\$ 3^{\circ} \mathrm{O}$ mediador, que atuará preferencialmente nos casos em que houver vínculo anterior entre as partes, auxiliará aos interessados a compreender as questóes e os interesses em conflito, de modo que eles possam, pelo restabelecimento da comunicação, identificar, por si próprios, soluçôes consensuais que gerem benefícios mútuos.

Art. 166. A conciliação e a mediação são informadas pelos princípios da independência, da imparcialidade, da autonomia da vontade, da confidencialidade, da oralidade, da informalidade e da decisão informada.

$\$ 1^{\circ}$ A confidencialidade estende-se a todas as informaçóes produzidas no curso do procedimento, cujo teor não poderá ser utilizado para fim diverso daquele previsto por expressa deliberação das partes.

$\$ 2^{\circ}$ Em razão do dever de sigilo, inerente às suas funçóes, o conciliador e o mediador, assim como os membros de suas equipes, não poderão divulgar ou depor acerca de fatos ou elementos oriundos da conciliação ou da mediação. $\$ 3^{\circ}$ Admite-se a aplicação de técnicas negociais, com o objetivo de proporcionar ambiente favorável à autocomposição.

$\$ 4^{\circ}$ A mediação e a conciliaçáo serão regidas conforme a livre autonomia dos interessados, inclusive no que diz respeito à definiçấo das regras procedimentais.

Art. 167. Os conciliadores, os mediadores e as câmaras privadas de conciliação e mediação serão inscritos em cadastro nacional e em cadastro de tribunal de justiça ou de tribunal regional federal, que manterá registro de profissionais habilitados, com indicação de sua área profissional.

$\$ 1^{\circ}$ Preenchendo o requisito da capacitação mínima, por meio de curso realizado por entidade credenciada, conforme parâmetro curricular definido pelo Conselho Nacional de Justiça em conjunto com o Ministério da Justiça, o conciliador ou o mediador, com o respectivo certificado, poderá requerer sua inscrição no cadastro nacional e no cadastro de tribunal de justiça ou de tribunal regional federal.

$\$ 2^{\circ}$ Efetivado o registro, que poderá ser precedido de concurso público, o tribunal remeterá ao diretor do foro da comarca, seção ou subseção judiciária onde atuará o conciliador ou o mediador os dados necessários para que seu nome passe a constar da respectiva lista, a ser observada na distribuição alternada e aleatória, respeitado o princípio da igualdade dentro da mesma área de atuaçáo profissional.

$\$ 3^{\circ}$ Do credenciamento das câmaras e do cadastro de conciliadores e mediadores constarão todos os dados relevantes para a sua atuação, tais como o número de processos de que participou, o sucesso ou insucesso da atividade, a matéria sobre a qual versou a controvérsia, bem como outros dados que o tribunal julgar relevantes. $\$ 4^{\circ}$ Os dados colhidos na forma do $\$ 3^{\circ}$ serão classificados sistematicamente pelo tribunal, que os publicará, ao menos anualmente, para conhecimento da população e para fins estatísticos e de avaliação da conciliaçáo, da mediação, das câmaras privadas de conciliação e de mediação, dos conciliadores e dos mediadores.

$\$ 5^{\circ}$ Os conciliadores e mediadores judiciais cadastrados na forma do caput, se advogados, estaráo impedidos 
de exercer a advocacia nos juízos em que desempenhem suas funçóes.

$\$ 6^{\circ} \mathrm{O}$ tribunal poderá optar pela criação de quadro próprio de conciliadores e mediadores, a ser preenchido por concurso público de provas e títulos, observadas as disposiçôes deste Capítulo.

Art. 168. As partes podem escolher, de comum acordo, o conciliador, o mediador ou a câmara privada de conciliação e de mediação.

$\$ 1^{\circ} \mathrm{O}$ conciliador ou mediador escolhido pelas partes poderá ou não estar cadastrado no tribunal.

$\$ 2^{\circ}$ Inexistindo acordo quanto à escolha do mediador ou conciliador, haverá distribuição entre aqueles cadastrados no registro do tribunal, observada a respectiva formação.

$\S 3^{\circ}$ Sempre que recomendável, haverá a designação de mais de um mediador ou conciliador.

Art. 169. Ressalvada a hipótese do art. $167, \$ 6^{\circ}$, o conciliador e o mediador receberão pelo seu trabalho remuneraçáo prevista em tabela fixada pelo tribunal, conforme parâmetros estabelecidos pelo Conselho Nacional de Justiça.

$\$ 1^{\circ}$ A mediação e a conciliação podem ser realizadas como trabalho voluntário, observada a legislaçáo pertinente e a regulamentação do tribunal.

$\$ 2^{\circ}$ Os tribunais determinarão o percentual de audiências não remuneradas que deverão ser suportadas pelas câmaras privadas de conciliação e mediação, com o fim de atender aos processos em que deferida gratuidade da justiça, como contrapartida de seu credenciamento.

Art. 170. No caso de impedimento, o conciliador ou mediador o comunicará imediatamente, de preferência por meio eletrônico, e devolverá os autos ao juiz do processo ou ao coordenador do centro judiciário de solução de conflitos, devendo este realizar nova distribuição.

Parágrafo único. Se a causa de impedimento for apurada quando já iniciado o procedimento, a atividade será interrompida, lavrando-se ata com relatório do ocorrido e solicitaçáo de distribuição para novo conciliador ou mediador.

Art. 171. No caso de impossibilidade temporária do exercício da função, o conciliador ou mediador informará o fato ao centro, preferencialmente por meio eletrônico, para que, durante o período em que perdurar a impossibilidade, náo haja novas distribuiçóes

Art. 172. O conciliador e o mediador ficam impedidos, pelo prazo de 1 (um) ano, contado do término da última audiência em que atuaram, de assessorar, representar ou patrocinar qualquer das partes.

Art. 173. Será excluído do cadastro de conciliadores e mediadores aquele que:

I - agir com dolo ou culpa na condução da conciliação ou da mediação sob sua responsabilidade ou violar qualquer dos deveres decorrentes do art. $166, \$ \$ 1^{\circ}$ e $2^{\circ}$;

II - atuar em procedimento de mediação ou conciliação, apesar de impedido ou suspeito.

$\$ 1^{\circ}$ Os casos previstos neste artigo serão apurados em processo administrativo.

$\$ 2^{\circ} \mathrm{O}$ juiz do processo ou o juiz coordenador do centro de conciliação e mediação, se houver, verificando atuaçáo inadequada do mediador ou conciliador, poderá afastá-lo de suas atividades por até 180 (cento e oitenta) dias, por decisáo fundamentada, informando o fato imediatamente ao tribunal para instauraçáo do respectivo processo administrativo.

Art. 174. A União, os Estados, o Distrito Federal e os Municípios criarão câmaras de mediação e conciliação, com atribuiçóes relacionadas à soluçáo consensual de conflitos no âmbito administrativo, tais como:

I - dirimir conflitos envolvendo órgãos e entidades da administração pública;

II - avaliar a admissibilidade dos pedidos de resolução de conflitos, por meio de conciliação, no âmbito da administração pública;

III - promover, quando couber, a celebração de termo de ajustamento de conduta.

Art. 175. As disposições desta Seção não excluem outras formas de conciliação e mediação extrajudiciais vinculadas a órgãos institucionais ou realizadas por intermédio de profissionais independentes, que poderão ser regulamentadas por lei específica. 
Com efeito, mesmo antes desses marcos legais, tanto na Justiça Estadual como na Justiça Federal, já havia práticas de conciliação organizada. No Brasil, foi na década de 1980 que, devido à influência do movimento mundial de acesso à justiça, a reforma da legislaçáo brasileira permitiu novidades, tais como a instituição dos Juizados Especiais de Pequenas Causas.

Leslie Shérida Ferraz destaca que a busca pela conciliaçáo para solucionar os conflitos levados aos Juizados é a opção mais adequada, quando se levam em conta as próprias finalidades pelas quais essas Cortes foram criadas, no bojo de uma Justiça mais simples, rápida e informal ${ }^{12}$.

$\mathrm{Na}$ esfera Federal, a adoção dessas práticas se deu a partir de 2002, em processos do Sistema Financeiro de Habitação vinculados a Subseção de Maringá ${ }^{13}$ e, posteriormente, com a criação dos Juizados Especiais Federais previstos na Lei 10.259/2001, cujas demandas, em sua maioria, envolvem questóes previdenciárias.

Segundo o Conselho Nacional de Justiç̧ ${ }^{14}$ os números de conciliação vêm crescendo ao longo dos anos:

A conciliação é uma política adotada pelo CNJ desde 2006, com a implantação do Movimento pela Conciliação em agosto daquele ano. Anualmente, o Conselho promove as Semanas Nacionais pela Conciliação, quando os tribunais são incentivados a juntar as partes e promover acordos nas fases pré-processual e processual. Por intermédio da Resoluçáo CNJ 125/2010, foram criados os Centros Judiciários de Solução de Conflitos e Cidadania (CEJUSCs) e os Núcleos Permanentes de Métodos Consensuais de Solução de Conflitos (NUPEMEC), que visam fortalecer e estruturar unidades destinadas ao atendimento dos casos de conciliação.

Na Justiça Estadual, havia, ao final do ano de 2017, 982 CEJUSCs instalados. A Figura 114 indica o número de CEJUSCs em cada Tribunal de Justiça. Esse número tem crescido ano após ano. Em 2014 eram 362 CEJUSCs, em 2015 a estrutura cresceu em 80,7\% e avançou para 654 centros. Em 2016 o número de unidades aumentou para 808 e em 2017 chegou a 982.

A Figura 115 traz o percentual de sentenças homologatórias de acordo proferidas, comparativamente ao total de sentenças e decisōes terminativas. Em 2017 foram 12,1\% sentenças homologatórias de acordo, valor que vem crescendo nos dois últimos anos - em 2015 era de $11,1 \%$ e em $2016,11,9 \%$. Na fase de execução as sentenças homologatórias de acordo corresponderam, em 2017, a 6,0\%, e na fase de conhecimento, a $17,0 \%$.

Parágrafo único. Os dispositivos desta Seção aplicam-se, no que couber, às câmaras privadas de conciliação e mediação. 12 FERRAZ, Leslie Shérida. Acesso à Justiça. Uma análise dos Juizados Especiais Cíveis no Brasil. Rio de Janeiro: Editora FGV, 2010, p. 98/99.

13 CALMON, 2011, p. 107-114.

14 CNJ, 2018. Disponível em: http://www.cnj.jus.br/files/conteudo/arquivo/2018/08/44b7368ec6f888b 383f6c3de40c32167.pdf, p. 137. Acesso em: 12 julho 2019 
Outra pesquisa interessante, publicada pelo $\mathrm{CNJ},{ }^{15}$ intitulada de "Mediação e conciliaçáo avaliadas empiricamente", concebida pelo Departamento de Pesquisas Judiciárias do Conselho Nacional de Justiça (DPJ/CNJ), traz como um dos grandes benefícios da solução consensual a redução do tempo de duração dos processos, representando, em média, uma tramitação em metade do tempo se comparado àqueles feitos em que não houve conciliação, destacamos:

A duração média observada no conjunto de todos os processos foi igual a 1.019,5 dias, o que corresponde a 2,8 anos aproximadamente. Considerando a análise por tipo de processo, observa-se que a duração média de processos homologados é 585 dias (aproximadamente 1 ano e meio) enquanto que para processos não homologados a duração média é 1.061 dias (aproximadamente 3 anos). Como resultado, em média, o tempo de duração de processos homologados é aproximadamente a metade do tempo de duração de processos não homologados.

No que se refere à Justiça Federal, temos a Administração Pública como litigante, com demandas envolvendo, dentre outros, o INSS, a Caixa Econômica Federal e Conselhos de classe. Nesse ponto, a lei da mediação (art. 32) e o CPC (art. 174) estabelecem que a União, os Estados, o DF e os Municípios criariam câmaras de mediação e conciliação, com atribuiçóes relacionadas à solução consensual de conflitos no âmbito administrativo, para dirimir contendas envolvendo órgãos e entidades da Administração Pública e avaliar a admissibilidade dos pedidos de resolução de conflitos, por meio de conciliação, no âmbito da própria administração.

A indisponibilidade do interesse público não impede o uso da conciliação na esfera federal. Destaca-se que nas Centrais de Conciliação da Justiça Federal (CECON) há diariamente audiências conciliatórias envolvendo Sistema Financeiro de Habitação, contratos bancários, açôes previdenciárias, execução fiscal, danos morais e materiais, saúde, improbidade administrativa, conselhos profissionais, dentre outros.

Apesar de todas essas inquestionáveis vantagens, não se pode perder de vista também que a conciliaçáo/mediação não constitui uma panaceia para solucionar todos os problemas do Poder Judiciário. Existem, de fato, limites a esses meios alternativos de solução de conflitos.

A conciliação e a mediação devem ser consideradas ao lado de outras formas de solução de conflitos, constituindo uma das portas possíveis para se resolver o litígio das partes, porque - sob um olhar interno - existem situaçóes concretas que não devem ser levadas a esses mecanismos alternativos, quer pela complexidade, quer pelas posiçóes das próprias partes, sendo melhores resolvidas pela decisão de mérito no âmbito do Poder Judiciário. Sob um olhar externo, há quem sustente que a função do Judiciário não seria solucionar controvérsias, mas dar um significado adequado aos valores públicos e reorganizar instituiçôes a partir do desempenho desta função ${ }^{16}$.

15 CNJ, 2019, p. 96-97. Disponível em: http://www.cnj.jus.br/files/conteudo/arquivo/2019/05/ e1d2138e482686b

c5b66d18f0b0f4b16.pdf Acesso em: 15 outubro 2019.

16 GABBAY, Daniela Monteiro. Mediaçáo \& Judiciário no Brasil e nos EUA. Condiçóes, Desafios e Limites para a institucionalização da Mediação no Judiciário. Brasília: Gazeta Jurídica, 2013, p. 270/271. 
Apontam-se ainda outros limites à adoção desses meios alternativos de solução de conflitos, como o desequilíbrio de poder e a disparidade de recursos entre as partes, podendo influenciar o acordo de muitas maneiras. A parte mais pobre acaba tendo uma dificuldade maior de fazer uma análise prospectiva do litígio. A falta de recursos pode influenciar na própria qualidade de sua pretensão apresentada em Juízo. Ou mesmo o risco mais óbvio da necessidade do recebimento imediato da indenização por meio do acordo, aquém do desejado e razoável ${ }^{17}$.

Nesse sentido é que se deve cuidar para que a adoção de programas de meios alternativos de resoluçáo de conflitos não implique uma justiça de segunda classe, com a exclusão de uma parcela dos cidadãos, frustração do jurisdicionado e enfraquecimento do próprio Estado de Direito ${ }^{18}$.

No âmbito da Justiça Federal, a especificidade é que, em um dos polos da conciliação/ mediação, há uma instituição pública de âmbito federal, o que exige um esforço muito maior para a implementação de uma verdadeira política pública de busca de solução alternativa dos conflitos. É necessário que haja, verdadeiramente, uma tomada de decisão política por parte dos seus dirigentes para que, a partir daí, a mediaçáo e/ou a conciliação tornem-se mecanismos viáveis.

Enfim, a adoção da conciliação/mediação pode trazer grandes vantagens na busca de uma soluçấo adequada dos conflitos e que pode efetivamente contribuir para um efetivo acesso à justiça, desde que o método seja escolhido com razoabilidade, com parcimônia, sempre observando seus limites e atentando-se para os filtros de escolhas desses conflitos a serem submetidos à conciliação/mediação.

\section{ASPECTOS ATUAIS DOS MEIOS ALTERNATIVOS DE RESOLUÇÁO DE CONFLITOS: AS NOVAS TECNOLOGIAS E AS RESOLUÇÃO ON-LINE DE DISPUTAS}

Klaus Schawab ${ }^{19}$ nos lembra que "estamos no início de uma revolução que alterará profundamente a maneira como vivemos, trabalhamos e nos relacionamos", que chamou de Quarta Revoluçáo Industrial, caracterizada por uma profunda revolução tecnológica em diversas áreas, como a inteligência artificial, robótica, internet das coisas, nanotecnologia, armazenamento de energia, computação quântica, dentre outras. Elencou três características dessa nova revolução:

- Velocidade: ao contrário das revoluçóes industriais anteriores, esta

\footnotetext{
17 GABBAY, Daniela Monteiro. Mediação \& Judiciário no Brasil e nos EUA. Condições, Desafios e Limites para a institucionalização da Mediação no Judiciário. Brasília: Gazeta Jurídica, 2013, p. 272.

18 TARTUCE, Fernanda. Mediaçáo nos conflitos civis. São Paulo: Editora Método, 2008, p. 203/206.

19 SCHWAB, Klaus. A quarta Revoluçáo Industrial. Tradução de Daniel Moreira Miranda. São Paulo: Edipro, 2016, p. 12.
} 
evolui em um ritmo exponencial e não linear. Esse é o resultado do mundo multifacetado e profundamente interconectado em que vivemos; além disso, as novas tecnologias geram outras mais novas e cada vez mais qualificadas.

- Amplitude e profundidade: ela tem a revoluçáo digital como base e combina várias tecnologias, levando a mudanças de paradigma sem precedentes da economia, dos negócios, da sociedade e dos indivíduos. A revolução não está modificando apenas o "o que" e o "como" fazemos as coisas, mas também "quem" somos.

- Impacto sistêmico: ela envolve a transformação de sistemas inteiros entre países e dentro deles, em empresas, indústrias e em toda a sociedade ${ }^{20}$.

Se, de um lado, podemos vislumbrar que esse avanço exponencial, aliado à questão da interconectividade das relaçóes, traz um potencial gerador de conflitos; de outro lado, não se pode perder de vista que o uso dessas mesmas tecnologias pode contribuir para garantir que o acesso à justiça seja alcançado de forma mais eficiente, com a implantaçáo de meios alternativos de resolução de conflitos, mais céleres, baratos e efetivos.

Assim, para além das três ondas do acesso à justiça, antevistas por Brian Garth e Mauro Cappelletti, atualmente, existem vozes que mencionam uma "quarta onda de acesso à Justiça" e que estaria "consubstanciada no uso de tecnologia para moldar o novo cenário de resolução de disputas criado pelo avento da internet. Dado o estado atual da tecnologia e suas exponenciais possibilidades, calha perguntar quais seus impactos, atuais e futuros, para o sistema de Justiça como um todo" ${ }^{21}$.

É bem verdade que Kim Economides, participante originário do Projeto de Florença, já fazia menção a uma quarta onda de acesso à justiça, mas sem relacioná-la especificamente ao atual avanço tecnológico. Para esse autor, trata-se da "onda dos operadores do direito (inclusive dos que trabalham no sistema judicial) à justiça”, significando que não se pode desprezar a formação e a atuação adequadas desses operadores do direito para que os cidadãos efetivamente tenham acesso à justiça. Nas suas palavras:

Em vez de nos concentrarmos no lado da demanda, devemos considerar mais cuidadosamente o acesso dos cidadáos à justiça do lado da oferta, analisando dois níveis distintos: primeiro, o acesso dos cidadãos ao ensino do direito e ao ingresso nas profissóes jurídicas; segundo, uma vez qualificados, o acesso dos operadores do direito à justiça. Tendo vencido as barreiras para admissão aos tribunais e às carreiras jurídicas, como o cidadão pode se assegurar de que tanto juízes quanto advogados estejam equiparados para fazer "justiça”? ${ }^{22}$

20 SCHWAB, Klaus. A quarta Revoluçáo Industrial. Tradução de Daniel Moreira Miranda. São Paulo: Edipro, 2016, p. 13.

21 WOLKART, Erik Navarro; BECKER, Daniel. Da Discórdia analógica para a Concórdia digital. In: O Advogado do amanhấ: estudos em homenagem ao professor Richard Susskind. Coordenado por Bruno Feigelson, Daniel Becker e Giovani Ravagnani. São Paulo: Thomson Reuters Brasil, 2019, p. 116/117.

22 ECONOMIDES, Kim. Lendo as ondas do "Movimentos de Acesso à Justiça": epistemologia versus 
De todo modo, parece-nos que essa característica da utilização da tecnologia acaba por complementar a visão de Kim Economides, uma vez que exigirá do operador do direito, sem dúvida, uma nova postura e mesmo uma ressignificação de sua atuação profissional.

A respeito dos impactos do efetivo uso da tecnologia na prevenção e resolução de disputas, Erik Navarro Wolkart e Daniel Becker ${ }^{23}$ apontam alguns motores desta tendência, a saber: (i) a "virtualização dos órgãos jurisdicionais", que não se resume à digitalização do processo físico, mas abrange a utilização de todo um "aparato de computação cognitiva e automação de documentos para facilitar o processamento e julgamento de demandas". Nesse sentido, vale mencionar o Enunciado 25 da Jornada de Processo Civil do CJF: "As audiências de conciliação ou mediação, inclusive dos juizados especiais, poderáo ser realizadas por videoconferência, áudio, sistemas de troca de mensagens, conversa online, conversa escrita, eletrônica, telefônica e telemática ou outros mecanismos que estejam à disposição dos profissionais da autocomposição para estabelecer a comunicação entre as partes"; (ii) "algoritmos e decisóes", destacando que há hoje "algumas interessantes iniciativas de usos de softwares para a promoção do acesso à justiça", a exemplo da iniciativa do Supremo Tribunal Federal, que utiliza inteligência artificial para automatizar a classificação de processos ${ }^{24}$; (iii) "Big data e resolução de disputas": para esses autores, há uma quantidade massiva de dados, que devem ser usados para se buscar efetividades na resolução de disputas; por fim, (iv) "Democratização do acesso à informação jurídica", que sem dúvida constitui um dos pilares do acesso à justiça e que poderá ficar muito mais acessível com o uso da tecnologia, evitando um dos grandes obstáculos à realização do acordo, que é a assimetria de informação.

Sobre esse ponto, Erik Navarro Wolkart ressalta que a assimetria da informação é considerada, em geral, como a principal causa de insucesso na tentativa de realização dos acordos, destacando que:

Antes de o processo iniciar-se, e mesmo durante sua tramitaçáo, é muito provável que as múltiplas facetas da realidade tenham sido captadas pelas partes de modo diferente (incerteza interpretativa). Mais do que isso, é possível que algumas dessas lâminas da realidade

metodologia?. Cidadania, Justiça e Violência. Organizadores Dulce Pandolfi [et al]. Rio de Janeiro: Editora FGV, 1999.

23 WOLKART, Erik Navarro; BECKER, Daniel. Da Discórdia analógica para a Concórdia digital. In: O Advogado do amanhá: estudos em homenagem ao professor Richard Susskind. Coordenado por Bruno Feigelson, Daniel Becker e Giovani Ravagnani. São Paulo: Thomson Reuters Brasil, 2019, p. 117/123.

24 "Batizado de VICTOR, a ferramenta de inteligência artificial é resultado da iniciativa do Supremo Tribunal Federal, sob a gestão da Ministra Cármen Lúcia, em conhecer e aprofundar a discussão sobre as aplicaçōes de IA no Judiciário. Cuida-se do maior a mais complexo Projeto de IA do Poder Judiciário e, talvez, de toda a Administração Pública Brasileira.

$\mathrm{Na}$ fase inicial do projeto, VICTOR irá ler todos os recursos extraordinários que sobem para o STF e identificar quais estão vinculados a determinados temas de repercussão geral. Essa ação representa apenas uma parte (pequena, mas importante) da fase inicial do processamento dos recursos no Tribunal, mas envolve um alto nível de complexidade em aprendizado de máquina."

Disponível em: http://www.stf.jus.br/portal/cms/verNoticiaDetalhe.asp?idConteudo=380038. Acesso em: 5 out. 2019. 
tenham apresentando-se para apenas uma as partes, configurando-se como informaçáo privativa, totalmente desconhecida da outra parte (assimetria de informação propriamente dita) ${ }^{25}$.

Nessa perspectiva, é que se pode falar em um novo modelo de resolução alternativa: a "resolução on-line de disputas", a partir da incorporação de tecnologias de informação e comunicação às diferentes formas de resolução de conflitos, cujo potencial de efetivo acesso à justiça é inquestionável ${ }^{26}$. Também conhecida como Online Dispute Resolution (ODR).

Há, no entanto, diversos modelos que podem ser adotados, levando-se em conta evidentemente as tecnologias utilizadas. Desde a transposição para a internet ou telefonia móvel daqueles formatos de resolução alternativas de conflitos que antes dependiam de encontros presenciais, até mesmo a utilização de tecnologias de informação e comunicação para criar novas formas de resolução de conflitos, verdadeiramente. Nessas opçóes mais avançadas, utiliza-se da grande quantidade de dados disponíveis para realizar cálculos complexos, listar opçóes para as partes e mesmo modular a linguagem utilizada em suas comunicaçóes ${ }^{27}$.

Daniel Arbix e Andrea Maia destacam ainda que, para o sucesso desses novos modelos, é fundamental que o profissional tenha conhecimento de como "desenhar sistemas de resolução de disputas", identificando padróes dos conflitos em jogo, objetivos a serem alcançados, métodos adotados, dentre outros elementos importantes ${ }^{28}$.

Essa resolução on-line de disputas, na verdade, encontra terreno fértil no âmbito privado, como é o caso do e-Bay, para ficar em um dos cases mais emblemáticos ${ }^{29}$. Atualmente, há no Brasil uma proliferação de startups que se dedicam ao tema ${ }^{30}$. No entanto, observam-se

25 WOLKART, Erik Navarro. Análise Econômica do Processo Civil. Como a Economia, o Direito e a Psicologia podem vencer a Tragédia da Justiça. São Paulo: Thompsom Reuters Brasil, 2019, p. 354.

26 ARBIX, Daniel; MAIA, Andrea. Resolução on-line de disputas. In: O Advogado do amanhãa: estudos em homenagem ao professor Richard Susskind. Coordenado por Bruno Feigelson, Daniel Becker e Giovani Ravagnani. São Paulo: Thomson Reuters Brasil, 2019, p. 96/99.

27 ARBIX, Daniel; MAIA, Andrea. Resolução on-line de disputas. In: O Advogado do amanhá: estudos em homenagem ao professor Richard Susskind. Coordenado por Bruno Feigelson, Daniel Becker e Giovani Ravagnani. São Paulo: Thomson Reuters Brasil, 2019, p. 96/99.

28 ARBIX, Daniel; MAIA, Andrea. Resolução on-line de disputas. In: O Advogado do amanhá: estudos em homenagem ao professor Richard Susskind. Coordenado por Bruno Feigelson, Daniel Becker e Giovani Ravagnani. São Paulo: Thomson Reuters Brasil, 2019, p. 104/106.

29 "Diante do aumento significativo das disputas provindas do e-commerce, a loja virtual de compras e vendas, e-Bay, criada em 1995, é considerada a pioneira nas tratativas de resoluçóes on-line de conflitos (independente de qual seja o problema, sobre pagamento, condiçóes, entrega do objeto, entre outros), uma vez que criou uma plataforma digital para que os consumidores e vendedores pudessem resolver seus litígios amigavelmente e de forma on-line, sem necessidade de ingressar com uma ação judicial. (...)

Por meio da plataforma de resoluçáo de conflitos desenvolvida pelo e-Bay, a impressionante marca de mais de 60 milhoes de disputas foi resolvida até o ano de 2018. Assim, denota-se que essa plataforma digial tem funcionado muito bem, com significativo aumento pelo procura de uma solução de disputas que náo envolva o Poder Judiciário e que tem inspirado outras experidências de Online Dispute Resolution mundo afora, inclusive no Brasil". In: DA ROSA, Camila; SPALER, Mayara Guibor. Experiências Privadas de ODR no Brasil. Revista Jurídica da Escola Superior de Advocacia da OAB-PR, ano 3, número 3, dezembro/2018.

30 "Dentre as diferentes categorias de lawtechs e legaltechs associadas à AB2L, destaca-se a de Resolução de Conflitos On-line, cujo radar conta com 17 empresas, quais sejam: i) Sem Processo; ii) Concilie Online; iii) 
também avanços no Poder Público. Não obstante a solução consensual no âmbito judicial seja um grande avanço, a conciliação na esfera administrativa ainda se mostra como meio mais célere para solução dos litígios. Focado nesse pensamento, algumas soluçóes têm sido adotadas. Exemplo recente disso foi o termo de cooperação assinado entre a Senacon e o CNJ visando combater a chamada judicialização no consumo:

\begin{abstract}
A Secretária Nacional do Consumidor (Senacon) e o Conselho Nacional de Justiça $(\mathrm{CNJ})$ assinaram um termo de cooperação que pode ajudar no combate à judicialização das relaçóes de consumo e que, hoje, correspondem a $10 \%$ das 80 milhóes de açóes que tramitam no Judiciário brasileiro. A ideia é a seguinte: o cliente que recorrer à Justiça contra uma empresa será orientado a tentar um acordo pré-judicial na plataforma Consumidor.gov.br antes da abertura do processo. Ele náo será obrigado a fazer um acordo. Segundo o CNJ, a medida é válida para o chamado Processo Judicial Eletrônico (PJe), um sistema do $\mathrm{CNJ}$ em parceria com a $\mathrm{OAB}$ que permite realizar os atos processuais por meio digital, assim como realizar todo o acompanhamento da ação na Justiça. No futuro, o Consumidor.gov.br será integrado ao PJe. "Isso significa um esforço conjunto para a divulgação dessa forma alternativa de soluçóes de disputas, especialmente antes de utilizar o judiciário. No futuro, esse acordo vai significar uma integração de plataforma de modo que o processo eletrônico judicial vai estar ligado ao Consumidor.gov.br. Entấo, antes de entrar com uma ação no processo eletrônico, o consumidor terá a oportunidade de usar o '.gov' antes. Isso se quiser. Ela não é obrigada a nada”, explicou Luciano Benetti Timm, secretário nacional do Consumidor. Repercussóes $\mathrm{O}$ acordo foi celebrado por secretários e até o ministro da Justiça, Sérgio Moro. O secretário adjunto da Secretaria Especial de Programa, Pesquisas e Gestão Estratégicas (SEP) e juiz auxiliar da Presidência do CNJ, Carl Smith, armou que a medida pode ajudar na redução de açóes na Justiça. Hoje, segundo ele, estima-se a existência de $10 \%$ do acervo processual do país, que soma cerca de 10 milhóes de processos. "Por isso, todas as iniciativas que estimulem a desjudicialização impactam diretamente na garantia de direitos de rfoparcela significativa da populaçáo brasileira”, armou. Smith apontou o elevado grau de alinhamento entre as equipes do CNJ e do MJSP e enfatizou que, ao proporcionar maior celeridade à tramitação processual, a parceria dará relevante contribuição à garantia de direitos e fomentará a adoção de métodos de soluçáo consensual de controvérsias. A conselheira do CNJ Maria Tereza Uille destacou a importância do acordo de cooperação e lembrou que o Poder Judiciário precisa se ocupar de pautas significativas. "Precisamos fazer uma triagem na porta de entrada. Questóes de menor complexidade podem ser resolvidas por meio de conciliação", armou. O ministro da Justiça e Segurança Pública, Sérgio Moro, citou o Poder Judiciário
\end{abstract}

Juspro; iv) Leegol; v) Find Resolution; vi) Justto; vii) Mediaçáo Online; viii) Misc - Métodos Integrativos de Soluçóes de Conflitos; ix) Resolv Já; x) Juster; xi) Melhor Acordo; xii) Acordo Fechado; xiii) Acordo Net; xiv) Mediartech; xv) D'acordo; xvi) Itkos Mediação Inteligente; e xvii) Quero Reclamar.Com”. In: DA ROSA, Camila; SPALER, Mayara Guibor. Experiências Privadas de ODR no Brasil. Revista Jurídica da Escola Superior de Advocacia da $O A B-P R$, ano 3, número 3, dezembro/2018. 
como instrumento de garantia e proteção de direitos e ressaltou que, muitas vezes, a resolução do conflito tem custo até mesmo maior do que os valores em questáo. "Se tivermos alternativas mais baratas, por que não as incentivar?”, questionou Moro. Febraban assina termo A assinatura do acordo contou ainda com importante adesão da Federação Brasileira de Bancos (Febraban). O secretário-executivo do Banco Central, Adalberto Felinto Junior, citou que o estabelecimento de uma cooperaçáo como a assinada representa um avanço institucional. "É a prova que as instituições no Brasil ganham maturidade e se mostram capazes de ofertar um serviço público de grande qualidade", armou. O presidente da Febraban, Murilo Portugal, declarou que a adesão ao acordo é uma oportunidade para o setor bancário rearmar o compromisso com o diálogo, com o respeito e a transparência na relaçáo com os consumidores e com a resolução não judicial de conflitos. "A integração da plataforma 'consumidor.gov. br' com o PJe do CNJ tem esse 12/06/2019 Antes do processo judicial, o consumidor.gov.br https://www.consumidormoderno.com. br/2019/05/21/antes-processo-judicial-consumidor/3/5 objetivo de dispensar a necessidade de demandas que já sobrecarregam o nosso Judiciário", observou. ${ }^{31}$

Assim, em demandas envolvendo relaçóes de consumo, o cliente/consumidor, antes de ajuizar uma ação contra a empresa, será orientado a tentar um acordo pré-judicial na plataforma consumidor.gov.

O Consumidor.gov.br é um serviço público que permite a interlocução direta entre consumidores e empresas para soluçáo de conflitos de consumo pela internet. Monitorada pela Secretaria Nacional do Consumidor - Senacon - do Ministério da Justiça, Procons, Defensorias, Ministérios Públicos e também por toda a sociedade, esta ferramenta possibilita a resolução de conflitos de consumo de forma rápida e desburocratizada: atualmente, $80 \%$ das reclamaçóes registradas no Consumidor.gov.br sáo solucionadas pelas empresas, que respondem as demandas dos consumidores em um prazo médio de 7 dias, conforme dados constantes do próprio site:

O Consumidor.gov.br coloca as relaçóes entre consumidores, fornecedores e o Estado em um novo patamar, a partir das seguintes premissas:

i.Transparência e controle social são imprescindíveis à efetividade dos direitos dos consumidores;

ii.As informaçôes apresentadas pelos cidadãos consumidores são estratégicas para gestâo e execução de políticas públicas de defesa do consumidor;

iii.O acesso a informação potencializa o poder de escolha dos consumidores e contribui para o aprimoramento das relaçôes de consumo.

\footnotetext{
31 VENTURA, Ivan. Disponível em: http://www.jfsp.jus.br/documentos/administrativo/NUBI/
} Prospeccoes/27-05-2019/Antes_do_processo_judicial_o_consumidor.gov.br.pdf. Acesso em: 12 jul. 2019. 
Por se tratar de um serviço provido e mantido pelo Estado, com ênfase na interatividade entre consumidores e fornecedores para redução de conflitos de consumo, a participação de empresas no Consumidor.gov.br, só é permitida àqueles que aderem formalmente ao serviço, mediante assinatura de termo no qual se comprometem em conhecer, analisar e investir todos os esforços disponíveis para a solução dos problemas apresentados. O consumidor, por sua vez, deve se identificar adequadamente e comprometer-se a apresentar todos os dados e informaçóes relativas à reclamaçáo relatada.

A Secretaria Nacional do Consumidor do Ministério da Justiça é a responsável pela gestão, disponibilização e manutenção do Consumidor.gov.br, bem como pela articulação com demais órgãos e entidades do Sistema Nacional de Defesa do Consumidor que, por meio de cooperação técnica, apoiam e atuam na consecução dos objetivos do serviço.

A criação desta plataforma guarda relação com o disposto no artigo $4^{\circ}$ inciso V da Lei 8.078/1990 e artigo 7o, incisos I, II e III do Decreto $7.963 / 2013 . .^{32}$

Ressalte-se que já existe iniciativa de integração entre a plataforma Processo Judicial Eletrônico (PJe) e a plataforma "Consumidor.gov.br". Conforme afirmou o Ministro Dias Tofolli, "o nível tecnológico em que nos encontramos exige que a ampliação dos métodos auto compositivos, a partir de plataformas digitais, dê-se mediante interligação com o processo eletrônico" 33 .

Como se pode perceber, portanto, existem muitas possibilidades para se avançar no tema da resolução alternativa de solução de conflitos, por meio da utilização da tecnologia.

Não se ignora que os números de conciliação vêm crescendo, mas o fato é que, de um modo geral, os índices de acordo na Justiça brasileira ainda são baixos, de apenas 12,3\%; sendo certo que, na Justiça Federal, somente 8,4\% dos processos terminam em acordo, segundo dados do $\mathrm{CNJ}^{34}$. Portanto, há ainda muito a avançar.

\section{PRINCIPAIS ASPECTOS DA CONCILIAÇÃO NA JUSTIÇA FEDERAL}

A competência da Justiça Federal está prevista no artigo $109^{35}$ da Constituição da Repú-

32 Disponível em: https://www.consumidor.gov.br/pages/conteudo/publico/1 Acesso em: 15 out. 2019.

33 Disponível em: https://www.cnj.jus.br/projeto-piloto-marca-integracao-entre-pje-e-consumidor-govbr/. Acesso em: 15 out. 2019.

34 Justiça em Números 2019. Conselho Nacional de Justiça - Brasília: CNJ, 2019, p. 147.

35 Art. 109 - Aos juízes federais compete processar e julgar:

I - as causas em que a Uniấo, entidade autárquica ou empresa pública federal forem interessadas na condiçáo 
blica. Na Justiça Federal da $3^{a}$ Regiâo, a estrutura do seu programa de conciliação compreende o Gabinete da Conciliação (GABCON) e as centrais de conciliação (CECON).

Destacam-se dentro das competências da Justiça Federal litígios previdenciários envolvendo a concessão e a revisão de benefícios. Como requisito para qualquer demanda judiciária envolvendo benefícios previdenciários tem-se a necessidade do prévio requerimento administrativo, significando, com isso, que o Judiciário somente poderá ser acionado após a negativa do INSS em conceder o benefício ou a revisão pretendida. Requerimento administrativo, todavia, não se confunde com exaurimento da esfera administrativa. $\mathrm{Ou}$ seja, exige-se que o interessado pleiteie previamente perante a autarquia previdenciária, mas, havendo negativa do seu pedido, não se exige que sejam exauridos todos os recursos administrativos para possibilitar o pleito judicial.

Tais demandas, como dito, são inúmeras, principalmente perante os Juizados Especiais Federais. A Lei $n^{\circ} 10.259 / 2001$ que instituiu os Juizados Especiais Federais trouxe no parágrafo único do artigo $10^{36}$ previsão expressa para que os representantes judiciais da União, autarquias, fundaçôes e empresas públicas federais pudessem transigir, conciliar e desistir dos processos perante os Juizados Federais.

Essas demandas de massa ocupam grande parte da estrutura do programa de conciliação, permitindo, assim, que demandas como auxílio doença, aposentadoria por invalidez, apo-

de autoras, rés, assistentes ou oponentes, exceto as de falência, as de acidentes de trabalho e as sujeitas à Justiça Eleitoral e à Justiça do Trabalho;

II - as causas entre Estado estrangeiro ou organismo internacional e Município ou pessoa domiciliada ou residente no País;

III - as causas fundadas em tratado ou contrato da União com Estado estrangeiro ou organismo internacional;

IV - os crimes políticos e as infraçóes penais praticadas em detrimento de bens, serviços ou interesse da Uniáo ou de suas entidades autárquicas ou empresas públicas, excluídas as contravençóes e ressalvada a competência da Justiça Militar e da Justiça Eleitoral;

V - os crimes previstos em tratado ou convenção internacional, quando, iniciada a execuçáo no País, o resultado tenha ou devesse ter ocorrido no estrangeiro, ou reciprocamente;

V - A as causas relativas a direitos humanos a que se refere o $\$ 5^{\circ}$ deste artigo;

VI - os crimes contra a organização do trabalho e, nos casos determinados por lei, contra o sistema financeiro e a ordem econômico-financeira;

VII - os "habeas-corpus", em matéria criminal de sua competência ou quando o constrangimento provier de autoridade cujos atos não estejam diretamente sujeitos a outra jurisdição;

VIII - os mandados de segurança e os "habeas-data" contra ato de autoridade federal, excetuados os casos de competência dos tribunais federais;

IX - os crimes cometidos a bordo de navios ou aeronaves, ressalvada a competência da Justiça Militar;

$\mathbf{X}$ - os crimes de ingresso ou permanência irregular de estrangeiro, a execução de carta rogatória, após o "exequatur", e de sentença estrangeira, após a homologação, as causas referentes à nacionalidade, inclusive a respectiva opção, e à naturalização;

XI - a disputa sobre direitos indígenas.

36 Art. 10. As partes poderão designar, por escrito, representantes para a causa, advogado ou não.

Parágrafo único. Os representantes judiciais da União, autarquias, fundaçôes e empresas públicas federais, bem como os indicados na forma do caput, ficam autorizados a conciliar, transigir ou desistir, nos processos da competência dos Juizados Especiais Federais. 
sentadoria por idade, por tempo de contribuição, pensão por morte, salário maternidade, revisôes, sejam solucionadas em tempo muito mais rápido do que a um processo judicial como um todo. E qual a importância prática disso?

Vamos partir como exemplo um pedido de auxílio-doença. Normalmente o segurado procura um dos postos de atendimento do Instituto Nacional do Seguro Social (INSS), realiza um exame perante os peritos da autarquia e, caso náo seja constatada a incapacidade ou ausente algum outro requisito, como qualidade de segurado, por exemplo, o pedido é indeferido. Cabe a ele, entấo, recorrer dessa decisão e/ou ajuizar uma ação. Considerando que tenha sido ajuizada uma ação, aquela pessoa que apresenta problemas de saúde terá que se submeter a novos exames para convencimento do juízo. Pode ainda pedir uma tutela provisória. Aqui fazemos um corte epistemológico para mencionar uma questão importante que envolve a jurisprudência pátria e que vai implicar diretamente a solução consensual da demanda.

Durante muitos anos os pedidos envolvendo benefícios previdenciários, diante do evidente caráter social que envolvem, foram contemplados por tutelas provisórias que de certa forma amenizavam a demora natural do curso processual. Acontece que após a decisão no Repetitivo $692^{37}$ passou-se a entender que a reforma da decisão que antecipa a tutela obriga o autor da ação a devolver os benefícios previdenciários indevidamente recebidos. Não obstante tal tema esteja novamente em discussão, ainda prevalece o decidido em aludido repetitivo. E o que isso traz como consequência no tema aqui abordado? A consequência é a seguinte: os juízes diante de tal entendimento passam a não conceder a tutela de urgência uma vez que, em tendo uma futura reversão do julgamento em grau recursal, as consequências de uma cassação da tutela serão muito mais drásticas do que a negativa inicial. É aqui que ganha força a conciliação logo no início do processo, reforçada com a previsão do artigo 334 do $\mathrm{CPC}$, na medida em que as partes passaráo por um processo conciliatório inicial e, obtida a conciliação, o benefício já será implantado sem o risco do processo durar anos e o requerente, acometido de uma doença incapacitante, ter que esperar até a decisão final para poder gozá-lo ou, em muitas vezes, habilitar os herdeiros para receber os atrasados em decorrência do óbito da parte autora.

Outro litigante habitual na Justiça Federal e grande atuante nas Centrais de Conciliação é a Caixa Econômica Federal. Os processos que envolvem essa entidade financeira vão desde financiamentos habitacionais até pedidos de danos morais e materiais por saques fraudulentos, negativação indevida, cobrança indevida. Saliente-se, todavia, que tal parte não figura apenas no polo passivo das demandas, muitas ações são decorrentes de inadimplemento de contratos bancários, imobiliários, financiamentos estudantis, etc.

No Manual de Mediação e Conciliação da Justiça Federal há menção expressa da crise do Sistema Financeiro de Habitação e a importância do uso de meios consensuais. Nesse ponto esclarece:

Contudo, também a via judicial se mostrou inapta a resolver o pro-

37 A reforma da decisão que antecipa a tutela obriga o autor da ação a devolver os benefícios previdenciários indevidamente recebidos. Disponível em: http://www.stj.jus.br/repetitivos/temas_repetitivos/pesquisa.jsp. Acesso em: 24 out. 2019. 
blema, em virtude de seu caráter eminentemente econômico e social. Evidentemente, jamais a questão poderia ser sanada pela concessão maciça de liminares para obstar o pagamento de prestaçóes ou impedir a execução extrajudicial, sob o argumento de as quantias exigidas excederem o devido, pois a dívida não se limitava ao valor da prestaçáo, mas abrangia também o saldo devedor - do qual a prestação é mera amortização - e outros encargos, como o prêmio de seguro. Tampouco a medida seria capaz de afetar a real causa do conflito, decorrente do descasamento de critérios de correçáo e periodicidade mencionados, bem como da perda da capacidade financeira dos mutuários por variadas causas.

Diante da complexidade e extensão dos fatores subjacentes ao conflito, é impensável contemplá-los nos estreitos limites de uma lide processual formal. Em uma circunstância como esta, é patente a diferença entre aquilo que é trazido ao Poder Judiciário e aquilo que compóe, efetivamente, o interesse das partes e fomenta o conflito.

Dessa maneira, é inevitável que, ausentes mecanismos formais para a resoluçáo dessa espécie de conflito e sendo atribuição do Estado sua resolução, à luz do princípio do acesso inafastável ao Judiciário (art. 5०, XXXV, CF) e do dever de o Estado buscar a solução pacífica dos conflitos (preâmbulo e art. $4^{\circ}$, VII, CF), deva-se tentar a solução consensual entre as partes. Não por acaso, a institucionalização do uso de meios consensuais na Justiça Federal teve início em processos relacionados ao Sistema Financeiro de Habitação. ${ }^{38}$

Deve-se ter em mente que esses ditos litigantes habituais projetam de antemão qual o resultado provável da demanda e, diante disso, se posicionam de forma proativa para o acordo quando a sucumbência é quase inevitável. Ainda assim, para o litigante inabitual ter a antecipação da solução é, sem dúvida, um fator que compensa essa desvantagem processual e, portanto, revela uma boa prática também nesses casos e que pode significar a superação de um dos prováveis obstáculos para um possível acordo, que é a assimetria das informaçóes.

Aliado a esse aspecto, é preciso que se comece a pensar em adotar soluções tecnológicas, que certamente serão mais céleres e econômicas. Por exemplo, poderia se pensar em uma plataforma digital de acordo no âmbito do próprio INSS, antes mesmo de o conflito chegar ao Judiciário. Ou mesmo uma plataforma digital, gerenciada pelo Poder Judiciário, integrando e facilitando a comunicação dos diversos atores envolvidos.

Nesse perspectiva, dessa maneira, é preciso louvar a recente iniciativa de criação de uma Estratégia Nacional Integrada para Desjudicialização da Previdência Social, com a participação dos principais atores envolvidos na questão: STF, CNJ, STJ, CJF, Ministério da Economia, Secretaria Especial de Previdência e Trabalho, AGU, DPU e INSS, estratégia essa que "foi desenhada a partir da necessidade de atribuir tratamento adequado às açóes

38 Disponível em: https://www.cjf.jus.br/cjf/corregedoria-da-justica-federal/centro-de-estudos-judiciarios-1/publicacoes-1/outras-publicacoes/manual-de-mediacao-e-conciliacao-na-jf-versao-online.pdf. Acesso em: 15 out. 2019. 
judiciais relativas à concessão e à revisão de benefícios previdenciários e assistenciais, as quais representam parcela significativa do acervo processual da Justiça Federal" ${ }^{39}$ Sobre ainda esse acordo, vale destacar que:

A estratégia tem como propósito identificar pontos de conflito e as reais causas da litigiosidade em previdência para subsidiar melhores práticas de gestâo e de políticas públicas. Também fazem parte do plano implantar medidas para prevenir açóes na Justiça, estimular a resolução por consenso e melhorar o processamento das açóes previdenciárias. ${ }^{40}$

Assim, no âmbito da Justiça Federal, para além das questôes envolvendo os facilitadores da conciliação em cada caso concreto, náo se pode perder de vista a necessidade de uma articulaçáo interinstitucional em caráter nacional para incentivar/viabilizar a utilização dos métodos adequados de resolução de conflitos.

\section{CONCLUSÃO}

$\mathrm{O}$ acesso à justiça não se limita ao acesso ao Judiciário, mas significa, de um modo mais amplo, o respeito ao direito de cada cidadáo de ter uma resposta do Estado. Isso quer dizer que a famigerada cultura da sentença nem sempre será a solução que melhor atenda ao anseio dos litigantes, sem, com isso, pretender-se esvaziar a importância de tal provimento.

O acesso à Justiça é muito mais a obtenção de tutela jurisdicional efetiva. Os meios consensuais de soluçáo de conflitos são instrumentos à obtençáo dessa tutela jurisdicional efetiva, é um mecanismo de acesso à justiça.

Soma-se a isso, atualmente, a possibilidade de incorporação de soluçóes tecnológicas, que a cada momento tornam-se mais presentes no nosso dia-a-dia, como aliás vêm sendo muito bem utilizadas no setor privado, mas que pode e deve ser incorporada também no setor público.

Como se pôde perceber das pesquisas realizadas pelo $\mathrm{CNJ}$, nos últimos anos, houve um avanço na utilizaçáo dos meios alternativos de resoluçáo de conflitos. Muito embora ainda se mostre um aumento tímido frente às suas possibilidades, principalmente no âmbito da Justiça Federal. A recente iniciativa de criação de uma Estratégia Nacional Integrada para Desjudicialização da Previdência Social se mostra muito promissora, na medida que nos parece essencial uma articulação interinstitucional para um maior êxito das conciliaçóes das demandas federais.

Não se está defendendo que a conciliação e a mediação sejam uma panaceia, como solu-

39 Disponível em: http://www.stj.jus.br/sites/portalp/Paginas/Comunicacao/Noticias/Ministro-Noronhaassina-acordo-de-estrategia-para-desjudicializacao-da-Previdencia-Social.aspx. Acesso em: 23 out. 2019.

40 Disponível em: http://www.previdencia.gov.br/2019/08/acordo-entre-governo-federal-e-judiciario-devereduzir-acoes-sobre-previdencia/. Acesso em: 23 out. 2019. 
ção de todos os problemas do Judiciário. São instrumentais da Justiça, do juiz, que pode, diante do caso concreto, fazer uso ou náo.

Assim, embora não seja a solução para a excessiva carga judiciária, os meios alternativos passam a ganhar maior corpo no judiciário nacional, seja pela institucionalização mediante inovaçâao legislativa pertinente, seja pela ampliação de sua aplicabilidade, hoje não mais como um instrumento voltado à atividade privada, mas também, de forma horizontalizada, envolvendo a administração pública e o poder público. O reflexo imediato é a solução mais célere das demandas de massa que hoje ganham em eficiência.

\section{REFERÊNCIAS}

ARBIX, Daniel; MAIA, Andrea. Resolução on-line de disputas. In: O Advogado do amanhá: estudos em homenagem ao professor Richard Susskind. Coordenado por Bruno Feigelson, Daniel Becker e Giovani Ravagnani. São Paulo: Thomson Reuters Brasil, 2019.

ANTES DO PROCESSO JUDICIAL O CONSUMIDOR.GOV. Disponível em: http://www.jfsp.jus.br/documentos/administrativo/NUBI/Prospeccoes/27-05-2019/Antes_do_processo_judicial_o_consumidor.gov.br.pdf.

CALMON, Eliana. A conciliação judicial na Justiça Federal. In. RICHA, Morgana de Almeida; PELUSO, Antonio Cezar (Coord.) Conciliaçáo e mediação: estruturação da política judiciária nacional. Rio de Janeiro: Forense, 2011. p. 107-114.

CAPPETTI, Mauro; GARTH, Bryant. Acesso à justiça. Tradução de Ellen Gracie Northfleet. Porto Alegre: Sérgio Antonio Fabris Editor, 2002.

CINTRA, Antonio Carlos Araujo; DINAMARCO, Cândido Rangel; GRINOVER, Ada Pellegrini. Teoria Geral do Processo. 27a edição. São Paulo: Malheiros, 2011.

CONSUMIDOR.GOV - Disponível em: (https://www.consumidor.gov.br/pages/conteudo/publico/1).

DA ROSA, Camila; SPALER, Mayara Guibor. Experiências Privadas de ODR no Brasil. Revista Jurídica da Escola Superior de Advocacia da OAB-PR, ano 3, número 3, dezembro/2018.

ECONOMIDES, Kim. Lendo as ondas do "Movimentos de Acesso à Justiça": epistemologia versus metodologia?. Cidadania, Justiça e Violência. Organizadores Dulce Pandolfi [et al]. Rio de Janeiro: Editora FGV, 1999.

FERRAZ, Leslie Shérida. Acesso à Justiça. Uma análise dos Juizados Especiais Cíveis no Brasil. Rio de Janeiro: Editora FGV, 2010.

GABBAY, Daniela Monteiro. Mediaçáo \& Judiciário no Brasil e nos EUA. Condiçôes, Desafios e Limites para a institucionalização da Mediação no Judiciário. Brasília: Gazeta 
Jurídica, 2013.

JUSTIÇA EM NÚMEROS. Disponível em: http://www.cnj.jus.br/files/conteudo/arquivo/2018/08/44b7368ec6f888b383f6c3de40c32167.pdf.

JUSTIÇA EM NÚMEROS 2019. Conselho Nacional de Justiça - Brasília: CNJ, 2019.

O MITO DE SÍSIFO - Disponível em: http://www.culturabrasil.org/mitodesisifo.htm.

MEDIAÇÃO E CONCILIAÇÃO AVALIADAS EMPIRICAMENTE Disponível em: https://www.cnj.jus.br/files/publicacoes/arquivo/d87ecfa91fdcada3c1795f522be42dcc_ 7772666f491fd94a642e05b394cff84a.pdf.

ONODERA, Marcus Vinicius Kiyoshi. Gerenciamento do processo e acesso à justiça. Belo Horizonte, Del Rey, 2017.

SCHWAB, Klaus. A quarta Revoluçáo Industrial. Tradução de Daniel Moreira Miranda. São Paulo: Edipro, 2016.

TAKAHASHI, Bruno; ALMEIDA, Daldeci Maria Santana de; GABBAY, Daniela Monteiro; ASPERTI, Maria Cecília de Araújo. Manual de Mediaçáo e Conciliaçáo da Justiça Federal, Conselho da Justiça Federal. Brasília, 2019. Disponível em: https://www.cjf.jus. $\mathrm{br} / \mathrm{cjf} /$ corregedoria-da-justica-federal/centro-de-estudos-judiciarios-1/publicacoes-1/outras -publicacoes/manual-de-mediacao-e-conciliacao-na-jf-versao-online.pdf. Acesso em: 10 jun. 2019.

TARTUCE, Fernanda. Mediaçáo nos conflitos civis. São Paulo: Editora Método, 2008.

VENTURA, Ivan. Disponível em: http://www.jfsp.jus.br/documentos/administrativo/ NUBI/Prospeccoes/27-05-2019/Antes_do_processo_judicial_o_consumidor.gov.br.pdf.

WATANABE, Kazuo. Acesso à Ordem Jurídica Justa. Belo Horizonte: Ed. Del Rey LTDA, 2019.

WATANABE, Kazuo - Disponível em: https://www.tjsp.jus.br/Download/Conciliacao/ Nucleo/ParecerDesKazuoWatanabe.pdf.

WATANABE, Kazuo. Política pública do poder judiciário nacional para tratamento adequado dos conflitos de interesse. In: RICHA M. A.; PELUSO A. C. Conciliação e mediação: estruturação da política judiciária nacional. Rio de Janeiro: Forense, 2011.

WOLKART, Erik Navarro. Análise Econômica do Processo Civil. Como a Economia, o Direito e a Psicologia podem vencer a Tragédia da Justiça. São Paulo: Thompsom Reuters Brasil, 2019.

WOLKART, Erik Navarro; BECKER, Daniel. Da Discórdia analógica para a Concórdia digital. In: O Advogado do amanhã: estudos em homenagem ao professor Richard Susskind. Coordenado por Bruno Feigelson, Daniel Becker e Giovani Ravagnani. São Paulo: Thomson Reuters Brasil, 2019. 